\title{
Expression of $\beta$-nerve growth factor and homeobox A10 in experimental cryptorchidism treated with exogenous nerve growth factor
}

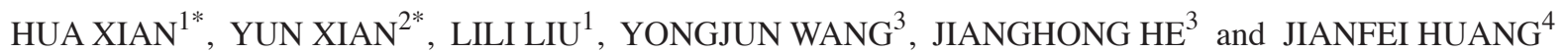 \\ ${ }^{1}$ Department of Pediatric Surgery, Affiliated Hospital of Nantong University; ${ }^{2}$ Department of Public Health College; \\ ${ }^{3}$ Jiangsu Key Laboratory of Neuroregeneration, Nantong University; ${ }^{4}$ Department of Pathology, \\ Affiliated Hospital of Nantong University, Nantong, Jiangsu 226001, P.R. China
}

Received January 27, 2014; Accepted October 24, 2014

DOI: $10.3892 / \mathrm{mmr} .2014 .3005$

\begin{abstract}
With the exception of standard inguinal orchidopexy, treatment of cryptorchidism with human chorionic gonadotropin has been performed for several years; however, its side effects have limited its application. The $\beta$-nerve growth factor (NGF) and homeobox A10 (HoxA10) genes are closely associated with the development of the testes. To the best of our knowledge, whether exogenous NGF alters the endogenous levels of NGF and HoxA10 in cryptorchidism in rats remains to be elucidated. The aim of the present study was to evaluate the gene and protein expression of NGF and HoxA10 in experimental cryptorchidism following treatment with exogenous NGF. A unilateral mechanical cryptorchidism model in Sprague-Dawley rats was established and different concentrations of exogenous NGF were administered to observe the effects of NGF on cryptorchidism. Changes in the gene and protein expression levels of NGF and HoxA10 in the cryptorchid tissues of each group were identified using one step reverse transcriptionquantitative polymerase chain reaction, in situ hybridization with digoxigenin-labeled- $\beta$-NGF RNA probes, immunofluorescence and immunohistochemistry, respectively. The expression levels of NGF and Hox A10 were markedly higher in the group treated with a high dose of exogenous NGF compared with the group treated with a low dose of exogenous NGF and the group treated with human chorionic
\end{abstract}

Correspondence to: Dr Jianfei Huang, Department of Pathology, Affiliated Hospital of Nantong University, 20 Xisi Road, Nantong, Jiangsu 226001, P.R. China

E-mail: ntyydoctor@126.com

*Contributed equally

Key words: $\beta$-nerve growth factor homeobox A10, cryptorchidism, in situ hybridization, immunohistochemistry gonadotropin. These results confirmed the potential therapeutic effect of exogenous NGF in human cryptorchidism.

\section{Introduction}

Cryptorchidism, also termed undescended testes, is the failure of one or two testes to descend into the scrotum. The testes first develop in the abdomen prior to birth and then descend into the scrotum. As the most common disorder of the male endocrine glands, cryptorchidism affects $2-4 \%$ of male infants, particularly premature infants (1-3). It is a well-established risk factor for later sub-fertility and testicular cancer in adulthood $(2,4)$. The failure of the testes to descend into the scrotum results in histological changes in the undescended testes $(5,6)$. With the exception of standard inguinal orchidopexy, cryptorchidism is treated using hormonal therapy. Treatment of cryptorchidism with human chorionic gonadotropin (HCG) was introduced in 1930 (7) and has been used for a number of years, particularly in Europe (1). However, there is increasing evidence that it has side effects on the germ cells $(7,8)$.

Cryptorchidism is a multifactorial disease involving multiple genes $(9,10)$. The mRNA and protein expression of $\beta$-nerve growth factor (NGF) and homeobox A10 (HoxA10) have been observed to decrease in the undescended testes $(11,12)$. NGF is considered to be one of the most important regulators of the growth, proliferation, differentiation and survival of nerves $(10,11,13)$. Furthermore, NGF has been detected in the testis (14-16) and is produced by male germ cells (17). The administration of exogenous NGF has been applied in certain animal models of the nervous system for $>35$ years, and specific clinical applications have been performed to investigate NGF delivery and its effects on the adult or developing nervous system $(18,19)$.

To the best of our knowledge, whether exogenous NGF alters the endogenous levels of NGF and HoxA10 in cryptorchidism in rats remains to be elucidated. The purpose of the present study was to establish a unilateral mechanical cryptorchidism model in Sprague-Dawley (SD) rats and to investigate the mRNA and protein expression of $\beta$-NGF and HoxA10 using electromicroscopical observation in the experimental cryptorchidism model following treatment with exogenous NGF. 


\section{Materials and methods}

Animals. Male 21-day-old SD rats $(\mathrm{n}=30)$ were obtained from the Experimental Animal Center of Nantong University (Nantong, China). The animals were maintained at controlled temperature $\left(25 \pm 2^{\circ} \mathrm{C}\right)$ and constant photoperiodic conditions (12 $\mathrm{h}$ light:12 $\mathrm{h}$ dark). The rats were given ad libitum access to food and water. The experimental procedure was designed in compliance with the Recommendations for the Care and Use of Laboratory Animals of the Local Ethical Committee at the Experimental Animals Center of Nantong University.

Unilateral cryptorchidism was induced by the surgical procedure described previously $(12,20)$. In brief, SD rats $(n=24)$ were anesthetized using Nembutal $(40 \mathrm{mg} / \mathrm{kg}$ body weight; concentration, 1\%; BOC Sciences, Shirley, NY, USA) and, following a small incision to the abdomen, the gubernaculum was cut on one side to displace the testis into the abdomen. Testis descent was prevented by closure of the inguinal canal on one side by suturing (Hualikang Medical Instrument Co., Nantong, China). Following surgery, the animals were housed and fed routinely with analgesics (Brufen, $1 \mathrm{mg} / \mathrm{ml}$; GlaxoSmithKline, Shanghai, China). The rats were then divided into four groups, a high-dose NGF group (HN group; $n=6$ ), low-dose NGF group (LN group; $\mathrm{n}=6$ ), human chorionic gonadotropin (HCG) group (HC group; $\mathrm{n}=6$ ) and negative control group (NC group; $\mathrm{n}=6$ ). In the HN and LN groups, 9,000 and 45,00 IU murine NGF (NOBEX; Xiamen Bioway Biotech, Xiamen, China) were injected intramuscularly each day for 5 days, respectively. This commenced from the second day following surgery. The $\mathrm{HC}$ group were administered with 400 IU HCG intramuscularly and the NC group were administered with normal saline intramuscularly. A total of six normal SD rats without surgery were used as a blank control group (B group) and were housed in the same cage.

The normal and undescended testes were removed and decapsulated 39 days following surgery at sexual maturity, which was calculated using the website, http://www.taletn. com/rats/age/. The samples were either stored at $-70^{\circ} \mathrm{C}$ or fixed for further use. All surgical procedures were performed under ether anesthesia (2-4\%; Jiangsu Qiangshen Chemical Co., Jiangsu, Chinag) and the animals were sequentially sacrificed by $\mathrm{CO}_{2}$ asphyxiation.

One step reverse transcription-quantitative polymerase chain reaction ( $R T-q P C R)$. Total RNA from the decapsulated testes was extracted using TRIzol reagent (Invitrogen Life Technologies, Carlsbad, CA, USA) according to the manufacturer's instructions. To avoid possible genomic DNA contamination, all the RNA samples were treated using RNase-free DNase (Promega Corporation, Madison, WI, USA). One step RT-qPCR was performed using a SensiMixTM One-Step kit (Quantace, London, UK) according to the manufacturer's instructions of the Rotor-Gene 3000 real-time DNA analysis system (Corbett Research, Sydney, Australia). For RT-qPCR examination of the temporal expression of $\beta$-NGF and Hox 10, the first-strand cDNA was synthesized using an Omniscript reverse transcription kit (Qiagen, Hilden, Germany) in a $20 \mu \mathrm{L}$ reaction system containing $2 \mu \mathrm{g}$ total RNA, $0.2 \mathrm{U} / \mu \mathrm{L}$ M-MLV reverse transcriptase, $0.5 \mathrm{mM}$ dNTP mix and $1 \mu \mathrm{M}$ Oligo-dT primer. The cDNA was diluted 1:5 prior to use in the RT-qPCR assays. Subsequently, the one step RT-qPCR was performed using a SensiMixTM One-Step kit (Quantace, London, UK) according to the manufacturer's instructions of the Rotor-Gene 3000 real-time DNA analysis system (Corbett Research). The mRNA expression levels of $\beta$-NGF and Hox 10 were calculated using Rotor-Gene Real-Time Analysis software 6.1 (Build 90; Corbett Research). The oligonucleotide primers of $\beta$-NGF, Hox 10 and glyceraldehyde-3-phosphate dehydrogenase (GAPDH) are listed in Table I. The amplification program consisted of $30 \mathrm{~min}$ at $42^{\circ} \mathrm{C}$ for reverse transcription and $2 \mathrm{~min}$ at $95^{\circ} \mathrm{C}$ for $\mathrm{Taq}$ activation, followed by 45 cycles of $95^{\circ} \mathrm{C}$ for $15 \mathrm{sec}, 58^{\circ} \mathrm{C}$ for $30 \mathrm{sec}$ and elongation at $72^{\circ} \mathrm{C}$ for $40 \mathrm{sec}$. GAPDH was used as an endogenous control gene for normalization.

In situ hybridization histochemistry with digoxigenin (DIG)-labeled- $\beta$-NGF RNA sense and antisense probes. The DIG-labeled- $\beta$-NGF RNA sense and antisense probes were generated using a DIG RNA Labeling kit (Roche Diagnostics $\mathrm{GmbH}$, Mannheim, Germany) according to the manufacturer's instructions. Briefly, the total RNA from the brain tissue of three SD rats was extracted using TRIzol reagent, as previously mentioned, and the cDNA fragment of $\beta$-NGF was obtained from the total RNA using RT-qPCR with the following primers: 5'-GATCGGCGTACAGGCAGAAT-3' and 5'-GGCTCGGCACTTGGTCTCAA-3'. The resulting product was then recovered from agarose gel and cloned into a pGEM-T easy vector (Promega Corporation) using T4 DNA ligase (Promega Corporation). The recombinant plasmid was transformed into the Escherichia coli strain, DH5a (Biomiga, Inc., San Diego, CA USA) and positive clones, confirmed by DNA sequencing, were transformed into $E$. coli Top10 (Biomiga, Inc.). The successfully-transformed E. coli Top10 was collected from a single colony and was then grown overnight at $37^{\circ} \mathrm{C}$ in Luria-Bertan medium supplemented with ampicillin (Sigma-Aldrich, St. Louis, MO, USA). Following plasmid extraction, the plasmid was linearized using the restriction enzymes, Apa I and Sal. Using Sp6 and T7 RNA polymerase, respectively, the DIG-labeled sense and antisense probes were transcribed in vitro using a DIG RNA Labeling kit according to the manufacturer's instructions. The sense probe was synthesized by T7 RNA polymerse, while the antisense probe by T3 RNA polymerse. In order to confirm the quality of the probes, an agarose gel was used, which revealed the antisense probe as a clear specific band and the sense probe also as a bright band

In situ hybridization (ISH) histochemistry was performed to detect the mRNA expression of $\beta$-NGF mRNA in the $4-\mu \mathrm{m}$ frozen sections from the decapsulated testes, which were fixed in freshly prepared $4 \%$ paraformaldehyde $(\mathrm{pH} 7.4)$ and stored at $4^{\circ} \mathrm{C}$ for $8 \mathrm{~h}$. The sections were then dried at $43^{\circ} \mathrm{C}$ overnight and washed twice with $0.1 \%$ diethypyrocarbonate-treated water. Following pre-hybridization for $2 \mathrm{~h}$, the sections were hybridized with DIG labeled- $\beta$-NGF RNA probes $(1 \mu \mathrm{g} / \mathrm{ml})$ in a humid chamber at $42^{\circ} \mathrm{C}$ for $18 \mathrm{~h}$. These sections were then washed twice with $2 \mathrm{X}$ saline sodium citrate (SSC) $/ 0.1 \%$ sodium dodecyl sulfate (SDS) buffer at $25^{\circ} \mathrm{C}$ for $5 \mathrm{~min}$ and with $1 \mathrm{X} \mathrm{SSC} / 0.1 \% \mathrm{SDS}$ at $60^{\circ} \mathrm{C}$ for $15 \mathrm{~min}$. Following incubation in inhibiting solution $(100 \mathrm{mM}$ maleic acid, $150 \mathrm{mM} \mathrm{NaCl}$ and $1 \%$ blocking reagent) at $37^{\circ} \mathrm{C}$ for $30 \mathrm{~min}$, the sections were incubated with the anti-DIG-AP (Roche Diagnostics, GmbH) 
at 1:5,000 dilutions in the inhibiting solution at $4^{\circ} \mathrm{C}$ overnight. The sections were then washed twice using the $100 \mathrm{mM}$ maleic acid buffer ( $\mathrm{pH} 7.5$ ) and $0.3 \%$ solution of Tween-20 (15 min each at $25^{\circ} \mathrm{C}$ ), followed by the addition of the detection buffer, containing $100 \mathrm{mM}$ Tris- $\mathrm{HCl}(\mathrm{pH} 9.5)$ and $100 \mathrm{mM} \mathrm{NaCl}$, for $5 \mathrm{~min}$. The ISH signals were detected using a coloring solution consisting of NBT/BCIP (Roche Diagnostics GmbH) in the dark for 3-12 h. The coloring reaction was terminated using $100 \mathrm{mM}$ phosphate-buffered saline (PBS; Hyclone Laboratories, Inc., Logan, UT, USA) and images were captured under a BX51 Olympus microscope (Olympus, Tokyo, Japan). A control experiment was performed in parallel using a sense probe. No significant $\beta$-NGF mRNA signal (blue) was observed. Bar $=100 \mu \mathrm{m}$.

Immunofluorescence (IF). The frozen decapsulated testicular tissues were cut into $4-\mu \mathrm{m}$ slices. The sections were then inhibited in PBS with 5\% goat serum (Gibco-BRL, Carlsbad, CA, USA) for $15 \mathrm{~min}$ at room temperature and incubated with goat anti-rat- $\beta$-NGF polyclonal antibody $(1: 400, \mathrm{R} \& \mathrm{D}$ Systems, Minneapolis, MN, USA) containing $1 \%$ bovine serum albumin (BSA) at $4^{\circ} \mathrm{C}$ for $24 \mathrm{~h}$. Following washing with PBS, these sections were incubated with monoclonal anti-fluorescein isothiocyanate-conjugated mouse anti-goat immunoglobulin G antibody (1:1,000; Sigma-Aldrich, St Louis, MO, USA) for $2 \mathrm{~h}$ at room temperature. The samples were then washed with PBS and the samples were observed using fluorescence microscopy (Zeiss Axioskop 40; Zeiss, Oberkochen Germany). As mentioned above, the IF experiments were repeated at least three times. Negative controls were included by replacement of the primary antibody with PBS.

Immunohistochemistry (IHC). The decapsulated testicular tissues were fixed in formalin and embedded in paraffin. The serial sections were cut at $4 \mu \mathrm{m}$ on a manual rotary microtome (Leica RM2235; Leica Microsystems GmbH, Wetzlar, Germany). IHC was performed on the sections using an Autostainer Universal Staining system (LabVision, Fremont, CA, USA). The sections were deparaffinized and peroxidase was quenched using methanol and $3 \% \mathrm{H}_{2} \mathrm{O}_{2}$ for $15 \mathrm{~min}$. For antigen retrieval, the sections were boiled under pressure in citrate buffer ( $\mathrm{pH}$ 6.0) for $3 \mathrm{~min}$. Nonspecific binding was inhibited using 5\% goat serum in PBS for 15 min and the tissues were incubated with rabbit anti-HoxA10 antibody $(1 \mu \mathrm{g} / \mathrm{ml}$; H-90; Santa Cruz Biotechnology, Inc., Santa Cruz, CA, USA) containing $1 \% \mathrm{BSA}$ at $4^{\circ} \mathrm{C}$ for $24 \mathrm{~h}$. Following washing with PBS, the sections were incubated with horseradish peroxidase-conjugated goat anti-rabbit antibody (DakoCytomation, Carpinteria, CA, USA) for $15 \mathrm{~min}$ at room temperature. To develop the colour, the sections were incubated for $15 \mathrm{~min}$ with diaminobenzidine solution (Kem-En-Tec Diagnostics, Taastrup, Denmark) and the sections were weakly counterstained using hematoxylin. Negative controls were included by replacement of the primary antibody with PBS.

The decapsulated testicular tissues were fixed in $1 \%$ paraformaldehyde $/ 1.25 \%$ glutaraldehyde in $0.1 \mathrm{M} \mathrm{PBS}$, post-fixed in $1 \%$ buffered osmium tetroxide, dehydrated through a graded ethanol series and embedded in Epon 812 epoxy resin. The $1.0 \mu \mathrm{m}$ sections for orientation were stained using toluidine
Table I. Oligonucleotide primers of $\beta-\mathrm{NGF}$, Hox10 and GAPDH.

\begin{tabular}{ll}
\hline Target & \multicolumn{1}{c}{ Sequence $\left(5^{\prime}-3^{\prime}\right)$} \\
\hline$\beta$-NGF & $\begin{array}{l}\text { Forward: ACCTCTTCGGACACTCTG } \\
\text { Reverse: GTGGCTGTGGTCTTATCTC }\end{array}$ \\
Hox10 & Forward: ACAAGCACACCACAATTCTCC \\
& Reverse:ATCCAAACAATGTCTCCCTTCTC \\
GAPDH & Forward: TCGTGGAGTCTACTGGCGTCT \\
& Reverse: CAACCTGGTCCTCAGTGTAG \\
\hline
\end{tabular}

$\beta$-NGF, $\beta$-nerve growth factor; Hox 10, homeobox 10.
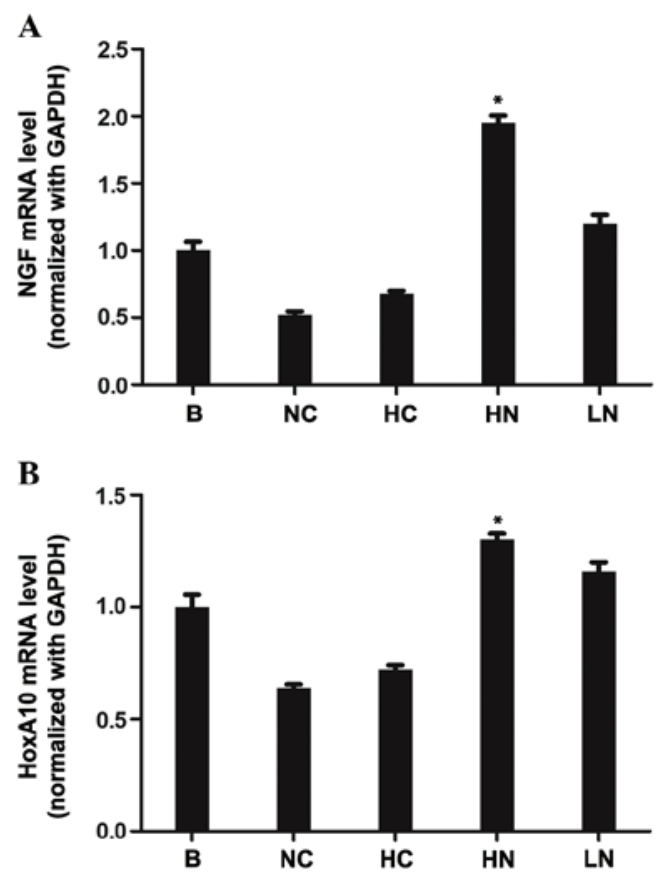

Figure 1. mRNA expression of NGF and HoxA10 in the testis. (A) mRNA expression of NGF in the testis (normalized to GAPDH expressed in the same sample) at day 39 following surgery. The highest mRNA expression level of NGF among the five groups was observed in the HN group, which was statistically significant. The mRNA expression levels of NGF were upregulated in the HN and LN groups. (B) mRNA expression of HoxA10 in the testis (normalized to GAPDH expressed in the same sample) at day 39 following surgery. The mRNA expression of HoxA10 in the HN group was the highest among the groups and was statistically significant. The mRNA expression of levels of HoxA10 were also increased in the HN and LN groups. ${ }^{*} \mathrm{P}<0.05$ in the HN group compared with the other groups. NGF, nerve growth factor; HoxA10, homeobox A10; HN, high-dose NGF; LN, low-dose NGF; HC, human chorionic gonadotropin; NC, negative control; B, blank control.

blue. The ultra-thin sections (50 $\mathrm{nm}$ ) were stained using uranyl acetate and lead citrate, followed by examination using a transmission electron microscope (JEM-1230; JEOL Ltd., Tokyo, Japan).

Statistical analysis. The mRNA expression levels of HoxA10 and $\beta$-NGF mRNA in the testis, measured using one step RT-qPCR, were assessed using a one way analysis of variance test paired with a t-test. $\mathrm{P}<0.05$ was considered to indicate a 

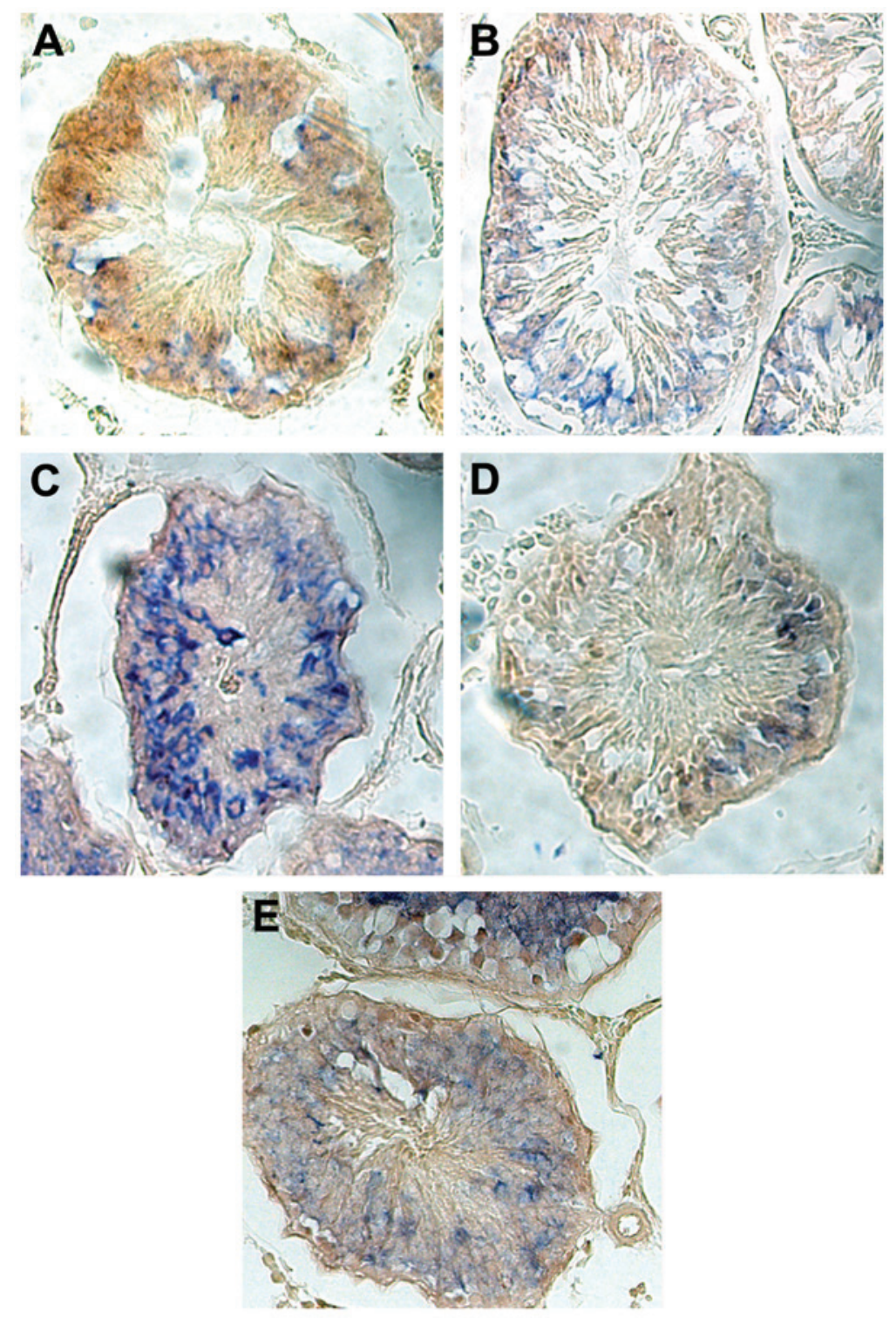

Figure 2. In situ hybridization with digoxigenin to detect the mRNA expression of $\beta$-NGF in the undescended testes. $\beta$-NGF mRNA signal (blue) was observed in the germ cell cytoplasm in the testes of the five groups. (A) Markedly reduced $\beta$-NGF mRNA expression in the NC group compared with the B group. (B) Elevated $\beta$-NGF mRNA expression in the human chorionic gonadotropin group compared with the NC group. (C) mRNA expression levels of $\beta$-NGF were highest in the high-dose NGF group compared with the other groups. (D) Enhanced mRNA expression of $\beta$-NGF in the low-dose NGF group compared with the NC group. (E) Normal mRNA expression of $\beta$-NGF in the B group. (Magnification, $\mathrm{x} 200$ ). NGF, nerve growth factor; NC, negative control; B, blank control.

statistically significant difference and the data were analyzed using STATA 9.0 software (Stata Corporation, College Station, TX, USA).

\section{Results}

Expression of HoxA10 and $\beta-N G F$ mRNA in the testes measured by one step RT-qPCR. Total RNA was extracted from the testis and subjected to one-step RT-qPCR to investigate the mRNA expression levels of HoxA10 and $\beta$-NGF in the groups with various treatments. The expression of HoxA10 and $\beta$-NGF were individually normalized to GAPDH, expressed as the ratio in the same sample at day 39 following surgery (Fig. 1A and B). Among the groups, the highest levels of mRNA expression of the two genes were observed in the HN group (HoxA10, $\mathrm{F}=125.58, \mathrm{P}<0.001$; and $\beta-\mathrm{NGF}, \mathrm{F}=49.03$, $\mathrm{P}<0.001)$. Compared with the testes in the $\mathrm{NC}$ group, the
mRNA expression of HoxA10 and $\beta$-NGF was clearly upregulated in the $\mathrm{HN}$ and $\mathrm{LN}$ groups.

mRNA expression of $\beta-N G F$ analyzed by ISH with $D I G$-labeled- $\beta$-NGF RNA probes. The mRNA signals of $\beta$-NGF were observed as blue staining in the cytoplasm of the germ cells in the testes. Compared with the NC group, the mRNA expression of $\beta$-NGF in the undescended testes increased on administering a high dose of exogenous NGF (Fig. 2A-E). This result was consistent with that of the above-mentioned one-step RT-qPCR.

Specific expression of $\beta$-NGF protein detected by IF. The $\beta$-NGF protein was stained in light green using IF, which revealed that the majority was localized in the cytoplasm of the germ cells, interstitial cells and leydig cells. The $\beta$-NGF protein was expressed in all the testicular tissues in each group, including 


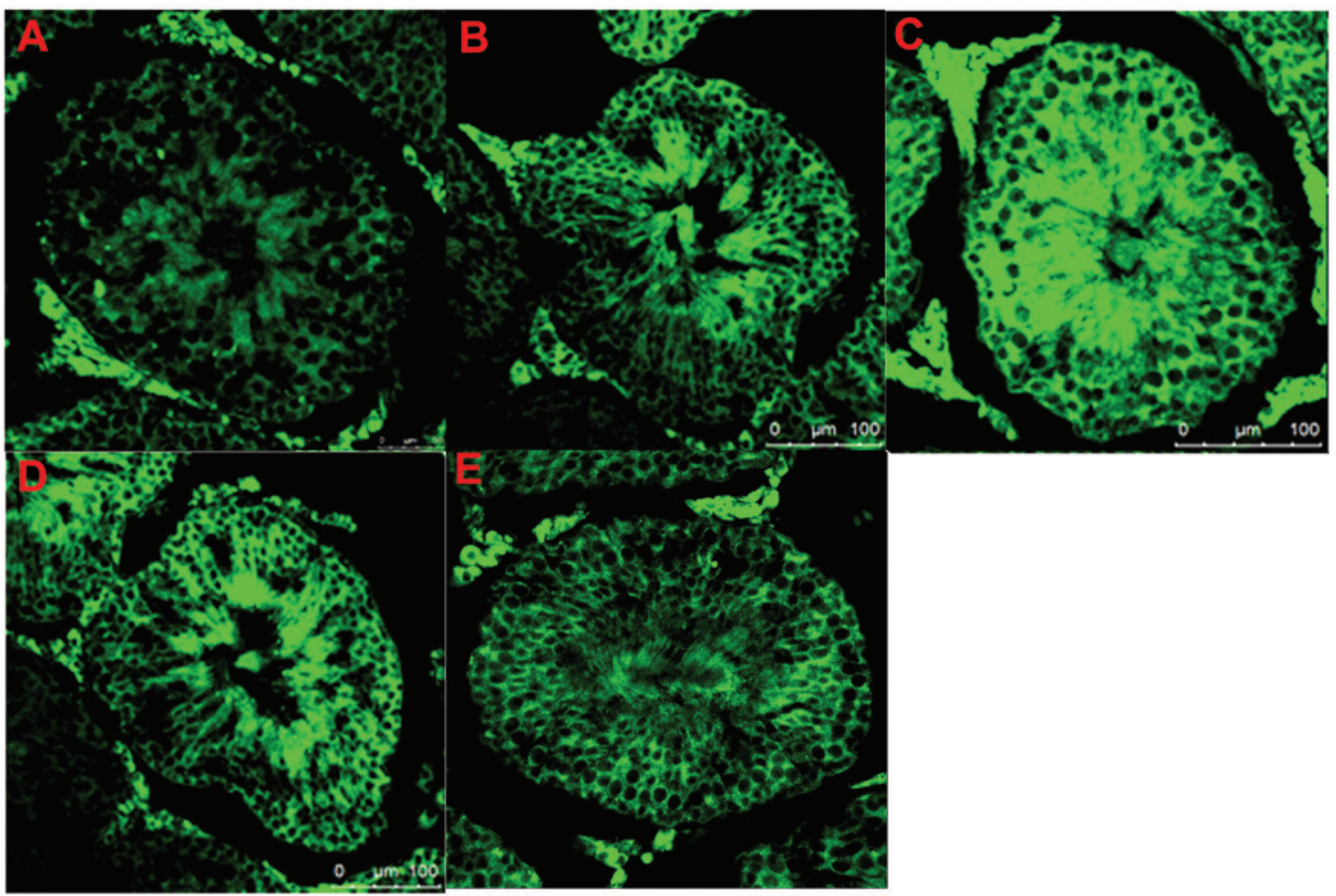

Figure 3. Immunofluorescence to detect the protein expression of $\beta$-NGF in the undescended testes. The $\beta$-NGF protein was observed (light green) in the cytoplasm of the germ cells, interstitial cells and leydig cells. (A) Marked reduction in the protein expression of $\beta$-NGF in the NC group compared with the B group. (B) Upregulation of $\beta$-NGF protein in the human chorionic gonadotropin group compared with the NC group. (C) Protein expression of $\beta$-NGF was highest in the high-dose NGF group compared with the other groups. (D) Protein expression of $\beta$-NGF was upregulated in the LN group compared with the NC group. (E) Upregulatino of $\beta$-NGF protein expression in the blank control compared with the NC group. (Magnification, x200). NGF, nerve growth factor; LN, low-dose NGF; NC, negative control; B, blank control.

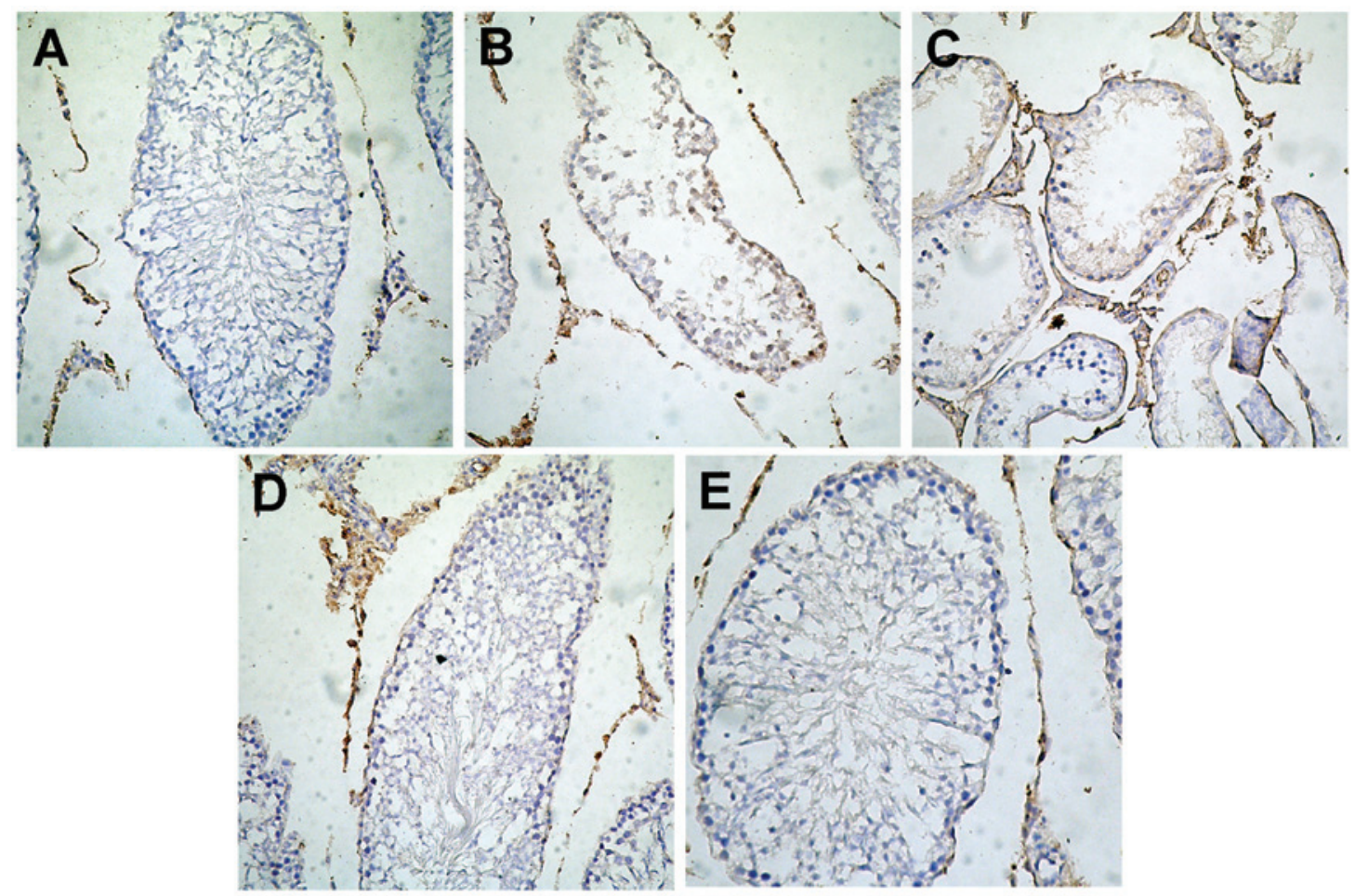

Figure 4. Immunohistochemical analysis to determine the protein expression of HoxA10 in the undescended testes. The immunohistochemical expression (brown) of HoxA10 was observed in the cell nucleus of the germ cells, interstitial cells and leydig cells. (A) Reduced expression of Hox A10 protein in the NC group compared with the B group. (B) Upregulation of the protein expression of HoxA10 in the human chorionic gonadotropin group compared with the NC group. (C) Protein expression of HoxA10 was highest in the high-dose NGF group compared with the other groups. (D) Elevated protein expression of HoxA10 was observed in the LN group compared with the B group. (E) The expression of HoxA10 in the B group was normal. (Magnification, x200). IHC, immunohistochemistry; HoxA10, homeobox A10; LN, low-dose NGF; NC, negative control; B, blank control. 


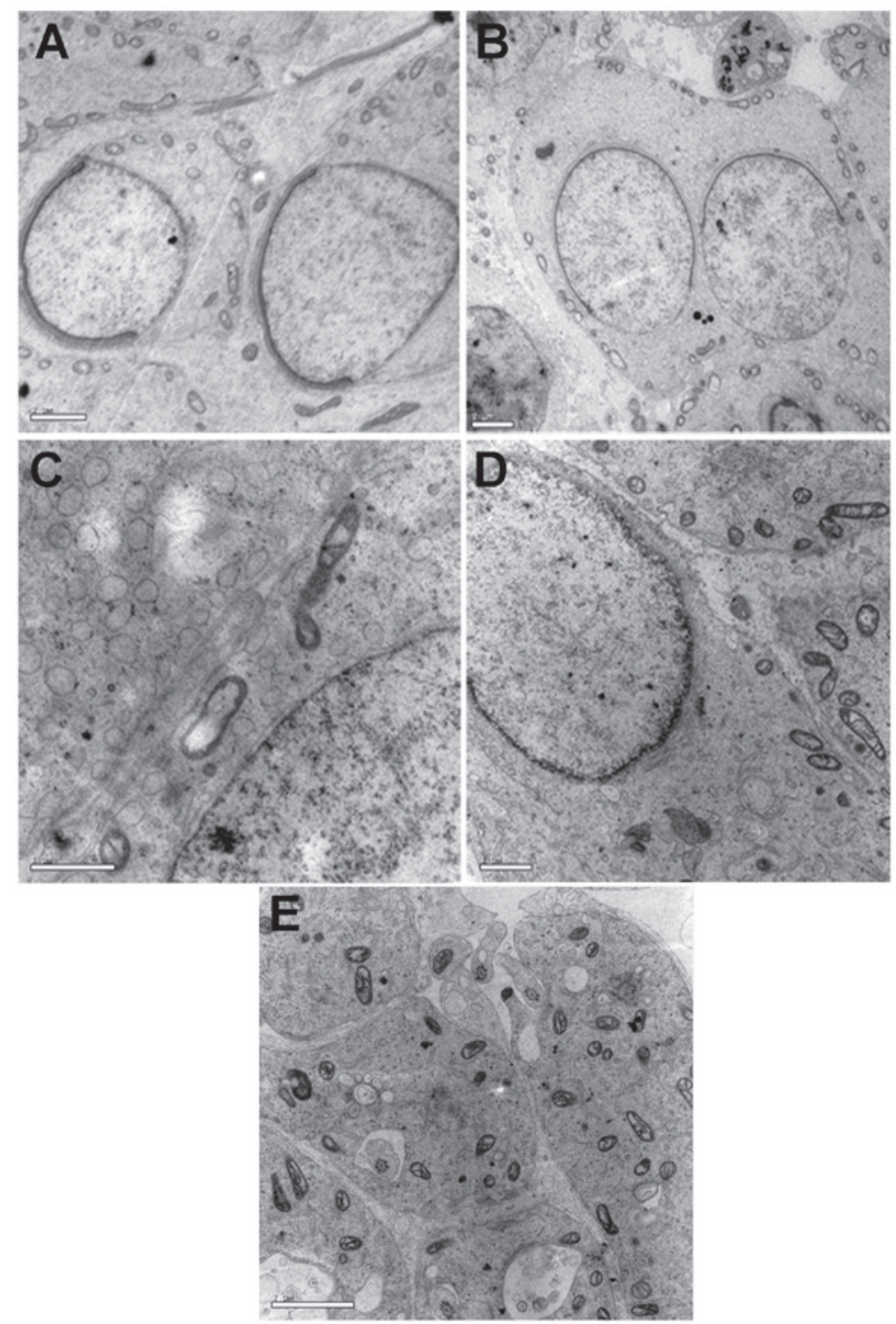

Figure 5. Microstructural changes in the testes observed in transmission electron microscope analysis following staining with uranyl acetate and lead citrate. (A) Reduced nuclear chromatin, vacuolar degeneration of ribosomes, widening of perinuclear space, nuclear pyknosis and damaged nuclear membrane were observed in the testicular tissues of the NC group compared with the B group. (B) Degree of injury in the testicular tissues of the human chorionic gonadotropin group was improved compared with the NC group. (C) Increased nuclear chromatin, decreased nuclear pyknosis, narrowing perinuclear space and an intact nuclear membrane were observed in the testicular tissues of the HN group, which was improved compared with the NC and LN groups. (D) Level of testicular tissue injury in the LN group was greater compared with the $\mathrm{HN}$ group. (E) Characteristic features of normal mature testicular tissues were observed in the B group. (Scale bar, $100 \mu \mathrm{m}$ ) HN. high-dose NGF; LN, low-dose NGF; NC, negative control; B, blank control.

the B group. It was notable that the protein expression of $\beta$-NGF in the undescended testis of the HN group was markedly higher compared with the NC, HC, LN and B groups(Fig.3 A-E).

Specific protein expression of HoxA10 measured by IHC. The positive staining, colored brown, of HoxA10 was mainly localized in the cell nucleus of the germ cells, interstitial cells and leydig cells in the testes. Notably, the protein expression of HoxA10 in the cryptorchidism of the HN group was markedly higher compared with the $\mathrm{NC}, \mathrm{HC}, \mathrm{LN}$ and $\mathrm{B}$ groups (Fig. 4A-E).

Transmission electron microscopy. Compared with the cells of the B group, the NC group exhibited pathological modifications, including reduced nuclear chromatin, vacuolar degeneration in ribosomes, thickened and damaged nuclear membrane, widening of the perinuclear space and nuclear pyknosis. Following treatment with a high dose of NGF, the testes of the HN group appeared to resemble normal testes, with fewer of the pathological changes mentioned above (Fig. 5A-E).

\section{Discussion}

In the majority of mammals, the testes are situated in the scrotum at the testicular temperature required in order to function (21). The unilateral mechanical cryptorchidism of SD rats, in which he distal tip of the gubernaculum was exposed extra-abdominally and was fixed to the fascia of the groin, is widely used as an experimental model to investigate the histopathologic changes and the molecular genetics of cryptorchidism $(5,20-22)$. It has been observed that $\beta$-NGF is 
involved in the regulation of spermatocyte differentiation by inhibiting secondary spermatocytes in metaphase. This leads to a reduction in round spermatid formation in co-cultures of pachytene spermatocytes and Sertoli cells (22). Furthermore, the NGF and HoxA10 genes are closely associated with the development of the testes $(9,10)$.

In the present study, NGF and HoxA10 mRNA and protein were observed in the undescended testes at sexual maturity. Changes of the two genes in the cryptorchid tissues of the different groups were identified using one step RT-qPCR, ISH with DIG-labeled- $\beta$-NGFRNA probes, IF and IHC. As expected, the expression levels of the two genes in the undescended testis were lower than that in the normal testis. Notably, the expression levels of these genes in the HN group were significantly higher than those in the NC, HC, B and LN groups. As NGF and HoxA10 genes are closely associated with the development of the testes, it was hypothesized that the increased expression of the two genes was an important effect of exogenous NGF in treating cryptorchidism in the present study.

In addition, the present study revealed microstructural changes in cryptorchidism using transmission electron microscopy. These changes may affect the development, maturation, apoptosis and necrosis of sperm organelles. The characteristic features of immaturity, including altered acrosomes, misshapen, round or elliptical nuclei with uncondensed chromatin, and the presence of cytoplasmic droplets, as previously described $(23,24)$, were also observed in the undescended testes of the present study. Additionally, less injury was observed in the HN group treated with a high dose of exogenous NGF compared with the groups treated with HCG or a low dose of exogenous NGF. These observations indicated the potential for using exogenous NGF to cure cryptorchidism instead of hormonal therapy using HCG.

Further studies are required to confirm these observations in the undescended testes. Investigation of the association between the gene expression of NGF and Hox A10 and factors, including caspase- 3 and Fas in undescended testes are also required to provide relevant information for elucidating the mechanisms involved in treating cryptorchidism with exogenous NGF administration.

\section{Acknowledgements}

The authors would like to thank the President of Nantong University, Professor Fei Ding (Key laboratory of Neuroregeneration), for critically reviewing this study. This study was supported by the Social Development Project (nos. S2008046 and HS2011047) in Nantong (Jiangsu, China).

\section{References}

1. Ashley RA, Barthold JS and Kolon TF: Cryptorchidism: pathogenesis, diagnosis, treatment and prognosis. Urol Clin North Am 37: 183-193, 2010.
2. Wohlfahrt-Veje C, Boisen KA, Boas M, et al: Acquired cryptorchidism is frequent in infancy and childhood. Int J Androl 32: 423-428, 2009

3. Sijstermans K, Hack WW, Meijer RW and van der Voort-Doedens LM: The frequency of undescended testis from birth to adulthood: a review. Int J Androl 31: 1-11, 2008.

4. Hadziselimovic NO, de Geyter C, Demougin P, Oakeley EJ and Hadziselimovic F: Decreased expression of FGFR1, SOS1, RAF1 genes in cryptorchidism. Urol Int 84: 353-361, 2010.

5. Zivkovic D, Bica DG and Hadziselimovic F: Effects of hormonal treatment on the contralateral descended testis in unilateral cryptorchidism. J Pediatr Urol 2: 468-472, 2006.

6. Ferlin A, Zuccarello D, Zuccarello B, Chirico MR, Zanon GF and Foresta C: Genetic alterations associated with cryptorchidism. JAMA 300: 2271-2276, 2008.

7. Thorsson AV, Christiansen P and Ritzén M: Efficacy and safety of hormonal treatment of cryptorchidism: current state of the art. Acta Paediatr 96: 628-630, 2007.

8. Kaleva M and Toppari J: Cryptorchidism: an indicator of testicular dysgenesis? Cell Tissue Res 322: 167-172, 2005.

9. Zhang L, Zheng XM, Hubert J, Zheng H, Yang ZW and Li SW: Prenatal exposure to diaethylstilbestrol in the rat inhibits transabdominal testicular descent with involvement of the INSL3/LGR8 system and HOXA10. Chin Med J (Engl) 122: 967-971, 2009.

10. Levi-Montalcini R and Hamburger V: Selective growth stimulating effects of mouse sarcoma on the sensory and sympathetic nervous system of the chick embryo. J Exp Zool 116: 321-361, 1951.

11. Levi-Montalcini R: The nerve growth factor 35 years later. Science 237: 1154-1162, 1987.

12. Xian H, Xian Y, Jiang CY, et al: Decreased expression of beta-nerve growth factor correlated with histological changes in a cryptorchidism rat model. Chin Med J (Engl) 125: 713-716, 2012.

13. Levi-Montalcini R, Dal Toso R, della Valle F, Skaper SD and Leon A: Update of the NGF saga. J Neurol Sci 130: 119-127, 1995.

14. Seidl K and Holstein AF: Evidence for the presence of nerve growth factor (NGF) and NGF receptors in human testis. Cell Tissue Res 261: 549-554, 1990.

15. Ayer-LeLievre C, Olson L, Ebendal T, Hallböök F and Persson H: Nerve growth factor mRNA and protein in the testis and epididymis of mouse and rat. Proc Natl Acad Sci USA 85: 2628-2632, 1988

16. Jin W, Tanaka A, Watanabe G, Matsuda H and Taya K: Effect of NGF on the motility and acrosome reaction of golden hamster spermatozoa in vitro. J Reprod Dev 56: 437-443, 2010.

17. Persson H, Ayer-Le Lievre C, Söder O, et al: Expression of beta-nerve growth factor receptor mRNA in Sertoli cells downregulated by testosterone. Science 247: 704-707, 1990.

18. Williams BJ, Eriksdotter-Jonhagen M and Granholm AC: Nerve growth factor in treatment and pathogenesis of Alzheimer's disease. Prog Neurobiol 80: 114-128, 2006.

19. Albeck D, Mesches MH, Juthberg S, et al: Exogenous NGF restores endogenous NGF distribution in the brain of the cognitively impaired aged rat. Brain Res 967: 306-310, 2003.

20. Hou W, Hu J, Li Y, et al: Altered expression of NDRG2 in the testes of experimental rat model of cryptorchidism. Urology 75: 985-991, 2010

21. Tena-Sempere M, Kero J, Rannikko A and Huhtaniemi I: Experimental cryptorchidism induces a change in the pattern of expression of $\mathrm{LH}$ receptor mRNA in rat testis after selective Leydig cell destruction by ethylene dimethane sulfonate. J Endocrinol 161: 131-141, 1999.

22. Perrard MH, Chassaing E, Montillet G, Sabido O and Durand P: Cytostatic factor proteins are present in male meiotic cells and beta-nerve growth factor increases mos levels in rat late spermatocytes. PLoS One 4: e7237, 2009.

23. Moretti E, Di Cairano G, Capitani S, Scapigliati G, Baccetti B and Collodel G: Cryptorchidism and semen quality: a TEM and molecular study. J Androl 28: 194-199, 2007.

24. Absalan F, Movahedin M and Mowla SJ: Germ cell apoptosis induced by experimental cryptorchidism is mediated by molecular pathways in mouse testis. Andrologia 42: 5-12, 2010. 